\title{
CARACTERIZAÇÃO DO DIÂMETRO DE GOTAS DE AEROSSÓIS EM INSETICIDAS DOMISSANITÁRIOS
}

\author{
A.R. Silva ${ }^{1}$, M.T. Leite ${ }^{2}$, M.C. Ferreira ${ }^{1}$, M.V. Tambellini ${ }^{1}$ \\ ${ }^{1}$ Universidade Estadual Paulista, Faculdade de Ciências Agrárias e Veterinárias, Departamento Fitossanidade, \\ Rod. Prof. Paulo Donato Castellane, s/no, CEP 14884-900, Jaboticabal, SP, Brasil. E-mail: adriana.agronomia \\ @terra.com.br
}

\section{RESUMO}

O objetivo deste trabalho foi caracterizar os aspectos relacionados ao diâmetro de gotas de aerossóis domissanitários. O espectro de gotas foi determinado num analisador de partículas (Mastersizer $\mathrm{S}^{\circledast}$, versão 2.19), utilizando o delineamento inteiramente casualizado em arranjo fatorial $6 \times 2$, com seis repetições. Avaliaram-se duas amostras, de seis diferentes marcas de aerossóis disponíveis no mercado e codificados como: BAT, REB, RCJ, RAT, SMI e M. Os seguintes parâmetros foram analisados: 1) a porcentagem do volume pulverizado contendo gotas com diâmetro igual ou inferior a $15 \mu \mathrm{m}$; 2) a amplitude relativa ao diâmetro de gotas do jato aplicado; e 3) os diâmetros de gotas para os quais 10\% $\left(\mathrm{Dv}_{0,1}\right), 50 \%\left(\mathrm{Dv}_{0,5}\right)$ e $90 \%\left(\mathrm{Dv}_{0,9}\right)$ dos volumes pulverizados apresentaram gotas de diâmetro inferiores. Os aerossóis avaliados apresentaram características de gotas que atenderam aos limites de tolerância vigente em resolução oficial da agência reguladora nacional.

PALAVRAS-CHAVE: Análise de partículas, DMV, uniformidade de gotas, poluentes ambientais, aerossol.

\section{ABSTRACT}

CARACTERIZATIONOFDROPLETDIAMETEROFHOUSEHOLDINSECTICIDE AEROSOLS. The objective of this work was to characterize the aspects related to the diameter of household aerosol droplets. The droplet spectra was determined in a particle size analyzer (Mastersizer $\mathrm{S}^{\circledR}$, version 2.19). The experiment was carried out in a completely randomized design, arranged on a $6 \times 2$ factorial scheme, with six replications. Two samples were evaluated, of 6 different aerosols available on the market and codified as: BAT, REB, RCJ, RAT, SMI and M. The following parameters were analyzed: 1 ) the percentage of the sprayed volume containing drops with diameter equal to $15 \mu \mathrm{m}$ or less; 2) the relative amplitude of the diameter of the droplets in the applied spurt; and the 3) the diameter of droplets for which $10 \%\left(\mathrm{Dv}_{0.1}\right), 50 \%\left(\mathrm{Dv}_{0.5}\right)$ and $90 \%\left(\mathrm{Dv}_{0.9}\right)$ of the sprayed volumes presented droplets with lesser diameters. The aerosols evaluated presented characteristics of droplets within the limits of effective tolerance according to the official resolution of the national regulating agency.

KEY WORDS: Particle analysis, DMV, droplet uniformity, environmental pollutants, aerosol.

\section{INTRODUÇÃO}

Atualmente, dentre os inseticidas domésticos, os aerossóis têm se destacado em meio às demais as formas de apresentação (DiEL et al., 2003). Embora a grande maioria desses produtos tenha em sua composição substâncias sintéticas derivadas de outras de origem natural, eles representam um importante perigo à saúde humana e ao ambiente (ZIEM, 2005). Devido à quantidade de ingrediente ativo liberado a cada aplicação e à frequência de uso, a exposição às gotículas de diâmetro diminuto contendo o ingrediente ativo no ambiente doméstico merece maior atenção (DAVIDSON et al., 2005).

O destino dessas gotas no ambiente depende das propriedades físicas da formulação, da pressão à qual a gota está submetida e das condições ambientais no momentodaaplicação,entreoutras(HANKS, 1995;PROKOP; KEJKLíĖEK, 2002). Gotasaquosas produzidasporaerossóis podem perder água através da evaporação, causando

${ }^{2}$ Universidade Federal de Uberlândia, Faculdade de Engenharia Química, Uberlândia, MG, Brasil. 
aumento na concentração da solução e a redução no seu tamanho (PHIPPs; GONDA, 1994).

Em geral, gotas com diâmetro inferior a $30 \mu \mathrm{m}$ não se depositam, deixando o ingrediente ativo em suspensão no ar, sobretudo em ambientes fechados. Estudos conduzidos na Alemanha demonstraram que partículas contendo ingrediente ativo de inseticidas, resultantes deaplicações domésticas, permaneceram em suspensão por duas semanas após a aplicação (Cox, 2002).

Apesar dos inseticidas sob a forma de aerossóis estarem presentes em cerca de 90\% dos domicílios (INFANTE-RIVARD et al., 1999; LANDRIGAN et al., 1999), há uma grande escassez de estudos sobre as diversas implicações douso desses produtos em ambientedoméstico. $\mathrm{O}$ crescente uso desses produtos fez com que a legislação brasileira atualizasse suas exigências em relação ao volumedegotascom diâmetroinferiora $15 \mu$ m presente nojatoaplicado(AgÊNCIANACIONALDE VIGILÂNCIASANITÁRIA, 2005). Portanto, o fornecedor da válvula atuadora é obrigadoa especificar a porcentagem de partículascom diâmetro inferior a $15 \mu \mathrm{m}$ e esta não deve ultrapassar $20 \%$ do volume total pulverizado.

O tipo e a geometria do jato definem a expansão do volume pulverizado pelo aerossol, enquanto o tamanho da gota determina a probabilidade da deposição porimpacto (NewMANet al., 2004). Devido ao diâmetro dessas partículas e, consequentemente, à sua aerodinâmica, o trato respiratórioéconsiderado oórgãoalvo para efeitos de inalação (CHEN et al., 1999; ELDER et al., 2006). Portanto, fazem-senecessários estudos a respeito do espectro das gotas contendo moléculas do ingrediente ativo dos aerossóis domissanitários que são transportadas por via aérea (COX, 2002; ZIEM, 2005). Nesse contexto, o objetivo deste trabalho foi caracteri- zar aspectos relacionados ao diâmetro de gotas de diferentes aerossóis domissanitários disponíveis no mercado brasileiro e a observância dos limites de diâmetro tolerados pela agência reguladora nacional.

\section{MATERIALEMÉTODOS}

A caracterização de aerossóis domissanitários foi realizada no Laboratório de Análise do Tamanho de Partículas(LAPAR), do Departamento Fitossanidade da UNESP, Campus de Jaboticabal, SP, em abril de 2006. Foram adquiridas duas amostras de aerossóis domissanitários, de seis marcas diferentes disponíveis no mercado (Tabela 1 ).

O espectro do diâmetro de gotas foi determinado de forma direta num analisador de tamanho de partículas por difração do feixe de luz de um laser (Mastersizer $\mathrm{S}^{\circledR}$, versão 2.19), ajustado para detectar gotas de 0,5 a $900 \mathrm{~mm}$. O diâmetro das gotas do jato pulverizado foi determinado através do desvio de trajetória sofrido pelo feixe de raios laser ao atingi-las. O grau de difração que o raio de luz sofre é inversamente proporcional ao diâmetro da partícula (ETHERIDGE et al., 1999).

Durante a análise, as partículas em suspensão (diâmetroinferior a $15 \mu \mathrm{m}$ ) foram retiradas através de um exaustor com coifa, evitando a superposição das gotas aspergidas sucessivamente e/ou a deposição destas sobre a unidade óptica, prejudicando a exatidão da leitura. Cada leitura do analisador foi realizada com intervalo de dois milissegundos. Por conseguinte, foram realizadas 500 leituras por segundo. As análises foram realizadas com as amostras em posição vertical, a $40 \mathrm{~cm}$ do feixe laser.

Tabela 1 - Código, produto comercial, ingredientes ativos e inertes dos aerossóis domissanitários avaliados. UNESP/ FCAV, Jaboticabal, 2006.

\begin{tabular}{|c|c|c|c|c|}
\hline Código & Produto comercial & Ingrediente ativo & $\begin{array}{l}\text { Data de fabricação } \\
\text { (Validade) }\end{array}$ & № Lote \\
\hline BAT & Baygon $^{\circledR}$ ação total & $\begin{array}{l}\text { Imiprotrina } 0,05 \% \\
\text { Ciflutrina } 0,015 \%\end{array}$ & $\begin{array}{l}6 / 6 / 2005 \\
(2 \text { anos })\end{array}$ & 5152003 \\
\hline REB & Rodasol $^{\circledR}$ energy ball & $\begin{array}{l}\text { Bioaletrina (93\%) 0,225\% } \\
\text { Bioresmetina (93\%) 0,042\% }\end{array}$ & $\begin{array}{l}18 / 8 / 2005 \\
(2 \text { anos })\end{array}$ & 2333861 \\
\hline $\mathrm{RCJ}$ & Raid $^{\circledR}$ casa e jardim & $\begin{array}{l}\text { Transflutrina } 0,03 \% \\
\text { Ciflutrina } 0,025 \%\end{array}$ & $\begin{array}{l}23 / 6 / 2005 \\
(2 \text { anos })\end{array}$ & 5173007 \\
\hline RAT & Rodasol $^{\circledR}$ ação total & $\begin{array}{l}\text { D-fenotrina } 0,10 \% \\
\text { Praletrina } 0,07 \%\end{array}$ & $\begin{array}{l}12 / 3 / 2006 \\
(2 \text { anos })\end{array}$ & 2722875 \\
\hline SMI & $\mathrm{SBP}^{\circledR}$ multi-inseticida (latas diferentes) & $\begin{array}{l}\text { D-aletrina } 0,135 \% \\
\text { d-tetametrina } 0,10 \%\end{array}$ & $\begin{array}{l}27 / 1 / 2006 \\
(2 \text { anos })\end{array}$ & 2622479 \\
\hline M & Mafú $^{\circledast}$ & $\begin{array}{l}\text { Propoxur } 0,75 \% \\
\text { Ciflutrina } 0,025 \%\end{array}$ & $\begin{array}{l}31 / 05 / 2005 \\
(2 \text { anos })\end{array}$ & 5147005 \\
\hline
\end{tabular}

${ }^{\circledR}$ Marca Registrada. 
Para avaliar os aerossóis em função da amostra foi utilizado o delineamento inteiramente casualizado em arranjo fatorial 6 × 2, com seis repetições (cada repetição simulou uma aplicação doméstica), sendo o primeiro fator os aerossóis avaliados e o segundo fator cada uma das amostras de cada aerossol. Antes de cada leitura a amostra foi agitada, conforme recomendadono rótulo dos produtos. Foram avaliados os seguintes aspectos relativos ao diâmetro das gotas produzidas: 1) o diâmetro da gota, para o qual $10 \%$ do volume pulverizado apresenta gotas de diâmetro inferior a ele $\left.\left(\mathrm{Dv}_{0,1}\right) ; 2\right)$ o diâmetro mediano volumétrico ou o diâmetro da gota, para o qual $50 \%$ do volume pulverizado apresenta gotas de diâmetroinferior a ele $\left(\mathrm{DMV} \mathrm{ouDv}_{0,5}\right)$;3) o diâmetro da gota, para o qual $90 \%$ do volume pulverizado apresenta gotas de diâmetro inferior a ele $\left(\mathrm{Dv}_{0,9}\right)$; 4$)$ a porcentagem do volume pulverizado com gotas com diâmetroigualou inferior a $15 \mu \mathrm{m} ; \mathrm{e} 5$ ) a amplitude relativa ao diâmetro de gotas do jato pulverizado.

A amplitude relativa ao diâmetro de gotas dojato pulverizado indica o grau de uniformidade do diâmetro das gotas produzidas. A uniformidademáxima do jato é obtida quando a amplitude relativa se iguala a zero. A amplitude relativa é dada por:

$$
A R=\frac{D v_{0,9}-D v_{0,1}}{D v_{0,5}}
$$

emque,

$\mathrm{AR}=$ amplitude relativa ao diâmetro de gotas do jato aplicado;
$\mathrm{Dv}_{0,1}=$ diâmetro da gota, para o qual $10 \%$ do volume pulverizado apresenta gotas de diâmetro inferior a ele;

$\mathrm{Dv}_{0,5}=$ diâmetro mediano volumétrico (DMV) ou diâmetro da gota, para o qual $50 \%$ do volume pulverizado apresenta gotas de diâmetro inferior a ele; e,

$\mathrm{Dv}_{0,9}=$ diâmetro da gota, para o qual $90 \%$ do volume pulverizado apresenta gotas de diâmetro inferior a ele.

Os dados de $\mathrm{Dv}_{0,1^{\prime}}, \mathrm{Dv}_{0,5^{\prime}}, \mathrm{Dv}_{0,9^{\prime}}$ porcentagem de gotas com diâmetro igual ou inferior a $15 \mu \mathrm{m}$ e a amplitude relativa foram submetidos à análise de variância e as médias foram comparadas pelo teste de Tukey $(\mathrm{P}<0,05)$.

\section{RESULTADOS}

A pressão inicial aferida nos diferentes tratamentos é apresentada na Figura 1. A variação observada entre as amostras de um mesmo produto pode ser considerada pequena, uma vez que o coeficiente de variação observado foi sempre menor que $5 \%$.

A amplitude de pressão observada entre os produtos não apresentou relação direta com o diâmetro de gotas. Isto pode ser observado no tratamento REB, que apresentou a maior pressão e a segunda menor porcentagem de gotas menores que $15 \mu \mathrm{m}$ e o maior diâmetro mediano volumétrico, não diferindo significativamente do tratamento SMI, que apresentou a segunda menor pressão.

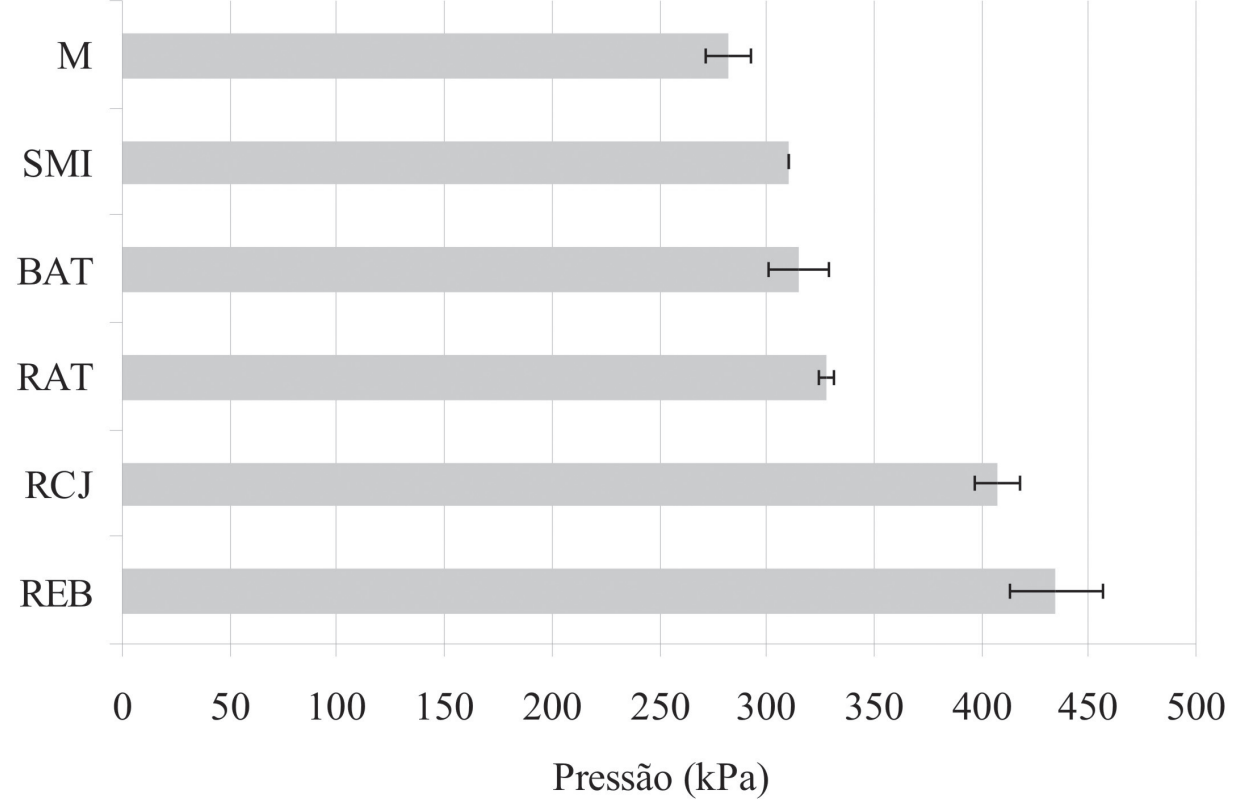

Fig. 1 - Pressão inicial $(\mathrm{kPa})$ aferida nos diferentes tratamentos e o desvio-padrão. Jaboticabal, 2006. 


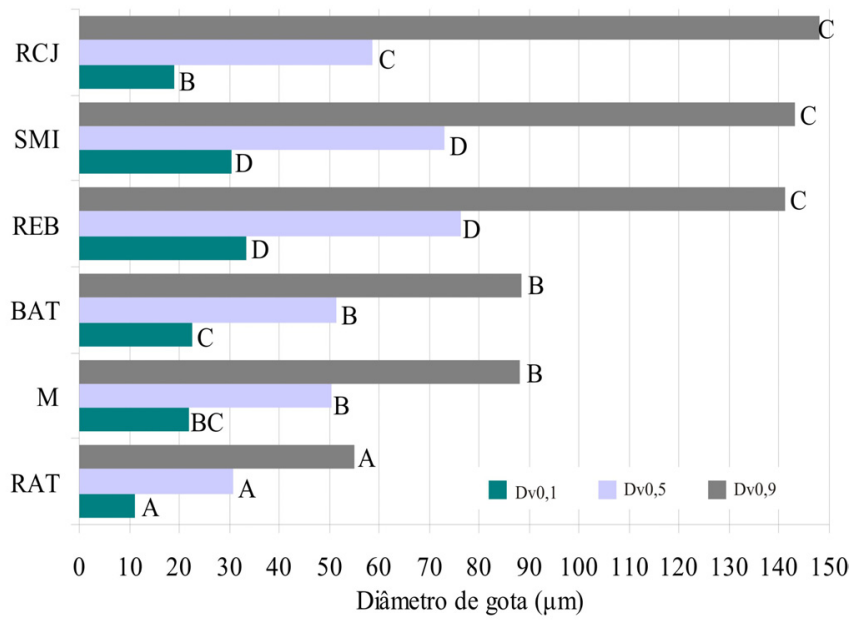

Fig. 2 - Diâmetro médio das gotas correspondentes aos volumes acumulados de $10\left(\mathrm{Dv}_{0,1}\right), 50\left(\mathrm{Dv}_{0,5}\right)$ e $90 \%\left(\mathrm{Dv}_{0,9}\right)$, avaliados pelo teste de Tukey $(\mathrm{P}<0,05)$. Jaboticabal, 2006.

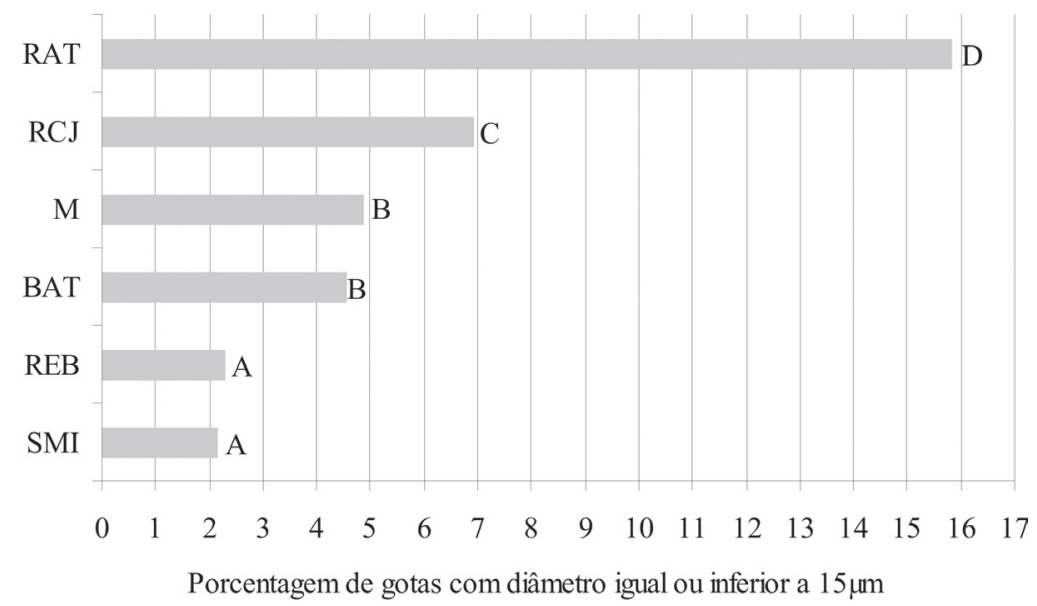

Fig. 3 - Porcentagem média do volume pulverizado com gotas com diâmetro igual ou inferior a 15 um nos diferentes aerossóis, avaliados pelo teste de Tukey (P < 0,05). Jaboticabal, 2006.

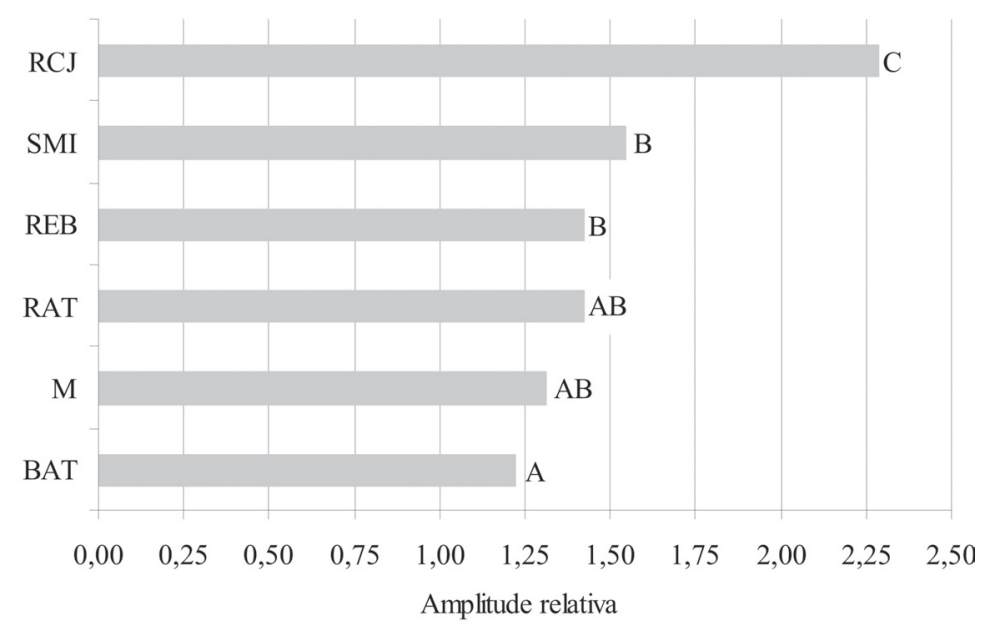

Fig. 4 - Amplitude relativa ao diâmetro de gotas do jato aplicado nos diferentes aerossóis, avaliados pelo teste de Tukey $(\mathrm{P}<0,05)$. Jaboticabal, 2006. 
A análise de variância apresentou efeito significativo $(\mathrm{P}<0,01)$ para os diferentes aerossóis. Para as amostras e os aerossóis em função das amostras não se verificaram efeitos significativos $(\mathrm{P}>0,05)$.

As médias dos diâmetros de gotas correspondentes aos volumes acumulados de 10, 50 e 90\% nos diferentes aerossóis avaliados diferiram significativamente ( $\mathrm{P}<0,05)$ entre si (Fig. 2).

Para o diâmetro aos quais 10 e $50 \%$ do volume pulverizado apresenta gotas de diâmetro inferior $\left(\mathrm{Dv}_{0,1}\right)$ o RAT apresentou o menor diâmetro, diferindo estatisticamente dos demais. O REB e oSMI apresentaram os maiores diâmetros, não diferindoestatisticamente entresi.

Para o diâmetroao qual $90 \%$ do volume pulverizado apresenta gotas de diâmetro inferior $\left(\mathrm{Dv}_{0,9}\right)$ o RAT apresentou diâmetro estatisticamente inferior aos demais.OREB, oSMIeo RCJapresentaram os maiores diâmetros, não diferindo estatisticamente entre si.

ORAT apresentou os menores diâmetros de gotas para os volumes acumulados de 10,50e $90 \%$, diferindo estatisticamente dos demais aerossóis avaliados, sendo que $90 \%$ do volume acumulado apresentou gotas com diâmetro inferior a $55 \mu \mathrm{m}$ (Fig. 1). Além disso, apresentou a maior porcentagem do volume pulverizado com gotas de diâmetro igual ou inferior a $15 \mu \mathrm{m}$, diferindo estatisticamente dos demais (Fig. 3).

OREB eoSMI apresentaram os maiores diâmetros degotas para os volumes acumulados de 10,50 e 90\%, não diferindo estatisticamente $(\mathrm{P}<0,05)$ entre si e diferindo dos demais aerossóis avaliados, excetuando-se o RCJ, quenão diferiu destes para o diâmetro de gota que corresponde a $90 \%$ do volume acumulado. Desta forma, tanto o REB quanto oSMI apresentaram as menores porcentagens dovolume pulverizadocom gotas de diâmetroigual ou inferior a $15 \mu \mathrm{m}$, diferindo estatisticamente dos demais $(\mathrm{P}<0,05)$.

A maior amplitude relativa ao diâmetro de gotas do jato aplicado foi apresentada pelo RCJ, diferindo estatisticamentedos demaisaerossóisavaliados(Fig.4). Os valores obtidos variaram de 1,22 a 2,29. Oaerossol que apresentou menor amplitude relativa do jato, e, conseqüentemente, maior homogeneidadedediâmetro de gotas, foi o BAT, não diferindo estatisticamente do M e do RAT. Estes, por sua vez, não diferiram do SMI e do REB.

\section{DISCUSSÃO}

Este trabalho caracterizou os aspectos relacionados ao diâmetro de gotas de diferentes aerossóis domissanitários disponíveis no mercado brasileiro em relação à observância dos limites de diâmetro tolerados pela agência reguladora nacional (AGÊNCIA NacionAl DE VigILÂNCIA SANITÁRIA, 2005).
Conforme RimeL; MoOre(1967), 93\% das gotículas que se fixam em insetos têm menos de $50 \mu \mathrm{m}$ de diâmetro, sendo que a maioria das gotículas se deposita nas asas e nas antenas (LOFGREN et al., 1973). A diferença no tamanho entre os insetos-alvo estudados pode ser relacionada às inconsistências observadas em alguns trabalhos. Mount (1970) estimou o diâmetro ótimo de gotas para controle de mosquitos entre 11 e $20 \mu \mathrm{m}$. MATTHEWs (2000) estimou a maior eficácia contra moscas e mosquitos entre 30 e $55 \mu \mathrm{m}$. Portanto, dentre os aerossóis avaliados, o RAT apresentou características relacionadas ao diâmetro de gotas no jato aplicado próximas às idealizadas por este autor (Figs. 1 e 2).

É importante considerar que a aplicação de inseticidas aerossóis é uma medida, fundamentalmente, adulticida. Portanto, o importante no jato pulverizado é a porcentagem de gotas capazes de aderir ao mosquito, isto é, as que têm menos de $20 \mu \mathrm{m}$ de diâmetro(Aragãoetal.,1988). Contudo, jato contendo gotas com diâmetro inferior a $30 \mu$ m pode representar risco de intoxicação, uma vez que estas gotas apresentam dificuldade de deposição em qualquer tipo de alvo, aumentando a possibilidade de inalação do ingredienteativo pelohomem(CHAIM etal.,1999; CLAY; Clarke, 1987; MAtThews, 2000).

A importância da amplitude relativa ao diâmetro degotas dojato pulverizado residena sua relação com a ocorrência de gotas menores que o diâmetro mediano volumétrico(DMV ou DV ${ }_{0,5}$ ) que são passíveis de inalação. Sendo assim, maior uniformidade significa também maior confiabilidade em um produto que apresente menos de $20 \%$ do volume pulverizado em gotas menores que $15 \mu \mathrm{m}$, pois isto refletirá também em um númeromenor dessas gotas. Numericamente, quanto maior o valor da amplitude relativa, maior será a faixa de diâmetro das gotas pulverizadas e, consequentemente, menor o número de gotas com diâmetro semelhante ao diâmetro mediano volumétrico (MATTHEWs, 2000).

Os tratamentos SMI e o REB apresentaram um espectro mais homogêneo, em relação ao diâmetro de gotas, queoRCJe, portanto, oferecem melhor qualidade de aplicação (CunHa et al., 2003).

Portanto, um determinado aerossol apresentará condições ideais necessárias à sua utilização se apresentar gotas com diâmetro mediano volumétrico dentro dos limites de segurança e na faixa de maior eficácia, ou seja, entre 15 e $20 \mu \mathrm{m}$.

\section{CONCLUSÕES}

Os aerossóis avaliados apresentaram características degotas que atenderam aos limites de tolerância vigente em resolução oficial da agência reguladora nacional. 


\section{REFEREANCIAS}

AGENCIA NACIONAL DE VIGILÂNCIA SANITÁRIA (Brasil). Resolução RDC No 326, 2005. Regulamento técnico para produtos desinfetantes domissanitários harmonizado no âmbito do Mercosul através da resolução GMC No 49/99. BRASÍLIA: Diário Oficial da União, v.218, n.1, 2005, p.40.

ARAGÃO, M.B.; AMARAL, R.S.; LIMA, M.M. Aplicação especial de inseticidas em saúde pública. Caderno de Saúde Pública, v.4, n.2, p.147-166, 1988.

CHAIM, A.; MAIA, A.H.N.; PESSOA, M.C.P.Y. Estimativa da deposição de agrotóxicos por análise de gotas. Pesquisa Agropecuária Brasileira, v.34, n.6, p.963-969, 1999.

CHEN, Y.S.; ZHOU, Y.; CHEN, B.T. Particle deposition in a cast of human oral airways. Aerosol Science and Technology, v.31, n.4, p.54-56, 1999.

CLAY, M.M.; CLARKE, S.W. Effect of nebulised aerosol size on lung deposition in patients with mild asthma. Thorax, v.42, p.190-194, 1987.

COX, C. Pyrethrins and pyrethrum. Journal of Pesticide Reform, v.22, n.1, p.14-20, 2002.

CUNHA, J.P.A.R.; TEIXEIRA, M.M.; COURY, J.R.; FERREIRA, L.R. Avaliação de estratégias para redução da deriva de agrotóxicos em pulverizações hidráulicas. Planta Daninha, v.21, n.2, p.325-332, 2003.

DAVIDSON, C.I.; PHALEN, R.F.; SOLOMON, P.A. Airborne Particulate Matter and Human Health: A Review. Aerosol Science and Technology, v.39, n.8, p.737-749, 2005.

DIEL, C.; FACCHINI, L.A.; DALL'AGNOL, M.M. Inseticidas domésticos: padrão de uso segundo a renda per capita. Revista de Saúde Pública, v.37, n.1, p.83-90, 2003.

ELDER, A.; GELEIN, R.; SILVA, V.; FEIKERT, T.; OPANASHUK, L.; CARTER, J.; POTTER, R.; MAYNARD, A.; ITO, Y.; FINKELSTEIN, J.; OBERDÖRSTER, G. Translocation of inhaled ultrafine manganese oxide particles to the central nervous system. Environmental Health Perspectives, v.114, n.8, p.1172-1178, 2006.

\section{ETHERIDGE, R.E.; WOMAC, A.R.; MUELLER, T.C.}

Characterization of the spray droplet spectra and patterns of four venturi-type drift reduction nozzles. Weed Technology, v.13, n.4, p.765-770, 1999.
HANKS, J.E. Effect of drift retardant adjuvant on spray droplet size of water and paraffinic oil at ultra low volume. Weed Technology, v.9, p.380-384, 1995.

INFANTE-RIVARD, C.; LABUDA, D.; KRAJINOVIC, M.; SINNETT, D. Risk of childhood leukemia associated with exposure to pesticides and with gene polymorphisms. Epidemiology, v.10, p.481-487, 1999.

LANDRIGAN, P.J.; CLAUDIO, L.; MARKOWITZ, S.B.; BERKOWITZ, G.S.; BRENNER, B.L.; ROMERO, H.; WETMUR, J.G.; MATTE, T.D.; GORE, A.C.; GODBOLD, J.H.; WOLFF, M.S. Pesticides and inner-city children: exposures, risks, and prevention. Environmental Health Perspectives, v.107, p.431-437, 1999. Suplemento 3.

LOFGREN, C.S.; ANTHONY, D.W.; MOUNT, G.A. Size of aerosol droplets impinging on mosquitoes as determined with a Scanning electron microscope. Journal of Economic Entomology, v.66, p.1085-1088, 1973.

MATTHEWS, GA. Pesticide Application Methods. London: Blackwell Science, 2000. 432p.

MOUNT, G.A. Optimum droplets size for adult mosquito control with space sprays or aerosols of insecticides. Mosquitoes News, v.30, p.70-75, 1970.

NEWMAN, S.P.; PITCAIRN, G.R.; DALBY, R.N. Drug delivery to the nasal cavity: in vitro and in vivo assessment. Critical Reviews in Therapeutic Drug Carrier Systems, v.21, n.1, p.21-66, 2004.

PHIPPS, P.R.; GONDA, I. Evaporation of aqueous aerosols produced by jet nebulizers: effects on particle size and concentration of solution in the droplets. Journal of Aerosol Medicine, v.7, n.3, p.239-258, 1994.

PROKOP, M.; KEJKLÍÈEK, R. Effect of adjuvants on spray droplet size of water. Research in Agricultural Engineering, v.48, n.4, p.144-148, 2002.

RIMEL, C.M.; MOORE, A.D. Spruce budworm mortality as a function of serial spray droplet size. Science, v.156, p.1250-1251, 1967.

ZIEM, G. Pesticide spraying and health effects. Environmental Health Perspectives, v.113, n.3, p.150, 2005.

Recebido em 11/7/07

Aceito em 22/7/09 